\title{
Calpain-Cleavage of $\alpha$-Synuclein
}

\section{Connecting Proteolytic Processing to Disease-Linked Aggregation}

Brian M. Dufty, ${ }^{\star}$ Lisa R. Warner, ${ }^{\star}$ Sheng T. Hou, ${ }^{\dagger}$ Susan X. Jiang, ${ }^{\dagger}$ Teresa Gomez-Isla, ${ }^{\neq}$ Kristen M. Leenhouts, ${ }^{*}$ Julia T. Oxford, ${ }^{*}$ Mel B. Feany, ${ }^{\S}$ Eliezer Masliah, ${ }^{\pi}$ and Troy T. Rohn*

From the Department of Biology," Boise State University, Boise, Idaho; the Experimental NeuroTherapeutics Laboratory, ${ }^{\dagger}$ National Research Council Institute for Biological Sciences, National Research Council Canada, Ottawa, Ontario, Canada; the Unidad de Memoria, ${ }^{\ddagger}$ Servicio de Neurologia, Hospital Santa Creu i Sant Pau, Barcelona, Spain; the Department of Pathology, Brigham and Women's Hospital, Harvard Medical School, Boston, Massachusetts; and the Department of Neurosciences and Neuropathology, "थ University of California, San Diego, La Jolla, California

Parkinson's disease (PD) and dementia with Lewy bodies (DLB) are both characterized pathologically by the presence of neuronal inclusions termed Lewy bodies (LBs). A common feature found in LBs are aggregates of $\alpha$-synuclein ( $\alpha$-Syn), and although it is now recognized that $\alpha$-Syn is the major building block for these toxic filaments, the mechanism of how this occurs remains unknown. In the present study, we demonstrate that proteolytic processing of $\alpha$-Syn by the protease calpain I leads to the formation of aggregated high-molecular weight species and adoption of a $\beta$-sheet structure. To determine whether calpaincleavage of $\alpha$-Syn occurs in PD and DLB, we designed site-directed calpain-cleavage antibodies to $\alpha$-Syn and tested their utility in several animal model systems. Detection of calpain-cleaved $\alpha$-Syn was evident in mouse models of cerebral ischemia and PD and in a Drosophila model of PD. In the human PD and DLB brain, calpain-cleaved $\alpha$-Syn antibodies immunolabeled LBs and neurites in the substantia nigra. Moreover, calpain-cleaved $\alpha$-Syn fragments identified within LBs colocalized with activated calpain in neurons of the PD and DLB brains. These findings suggest that calpain I may participate in the disease-linked aggrega- tion of $\alpha$-Syn in various $\alpha$-synucleinopathies. (Am J Pathol 2007, 170:1 725-1 738; DOI: 10.2353/ajpath.2007.061232)

The common pathological feature of Parkinson's disease (PD) and dementia with Lewy bodies (DLB) is the presence of Lewy bodies (LBs), and the primary structural components of LBs are fibrils composed primarily of $\alpha$-synuclein ( $\alpha$-Syn), a highly conserved 140-amino acid protein that is predominantly expressed in neurons and may play a role in synaptic plasticity and neurotransmission. ${ }^{1-3}$ Pathologically, both PD and DLB share LBs as a common feature; however, clinical features of these two diseases are distinct. PD is characterized as a neurodegenerative movement disorder presenting with rigidity, resting tremor, disturbances in balance, and slowness in movement. ${ }^{4}$ In contrast to $\mathrm{PD}, \mathrm{DLB}$ is characterized as a neurodegenerative cognitive disorder. DLB is the second most common form of degenerative dementia, accounting for up to $20 \%$ of cases in the elderly, and LBs in DLB are found in a more generalized area than in PD. ${ }^{5} \mathrm{~A}$ key feature found in LB disorders such as PD and LBD is aggregates of $\alpha$-Syn, and collectively, such diseases are referred to as $\alpha$-synucleinopathies. ${ }^{6}$ Numerous studies now support the hypothesis that $\alpha$-Syn aggregation is the key step driving pathology, cellular damage, and subsequent neuronal dysfunction. ${ }^{7-9}$ Although the majority of previous studies have focused on the aggregation of full-length $\alpha$-Syn, recent studies suggest that truncated forms of $\alpha$-Syn are of pathogenic significance: truncated species of $\alpha$-Syn are found in PD and DLB brains, ${ }^{10,11}$ and they promote the ability of full-length

Supported by the National Institutes of Health/National Center for Research Resources (grant P20RR016454 to T.T.R.).

Accepted for publication February 6, 2007

Supplemental material for this article can be found on http://ajp. amjpathol.org

Address reprint requests to Troy T. Rohn, Department of Biology, Science/Nursing Building, Room 228, Boise State University, Boise, ID 83725. E-mail address: trohn@boisestate.edu. 
$\alpha$-Syn to aggregate ${ }^{11-14}$ and enhance cellular toxicity. ${ }^{11,15}$ Moreover, expression of C-terminally truncated $\alpha$-Syn (1-120) in transgenic mice leads to the formation of pathological inclusions and to a reduction in striatal dopamine levels. ${ }^{16}$ The mechanisms governing the proteolytic cleavage of $\alpha$-Syn are not firmly established, but a potential candidate protease is calpain I. Calpain I represents one of a large family of intracellular calcium-dependent proteases whose cleavage of specific proteins has been implicated in physiological pathways and in numerous pathological diseases including Alzheimer's disease and stroke. ${ }^{17,18} \alpha$-Syn is a substrate for calpain cleavage, ${ }^{19,20}$ and calpaincleaved $\alpha$-Syn species are similar in molecular weight to truncated $\alpha$-Syn fragments that promote $\alpha$-Syn aggregation and enhance cellular toxicity. ${ }^{12,14,21}$ Herein, we demonstrate that calpain I fits the criteria of a protease capable of converting $\alpha$-Syn into its aggregated form after its cleavage in a cell-free system or in a cell model system consisting of SH-SY5Y neuroblastoma cells. Furthermore, we show that cleavage of $\alpha$-Syn by calpain occurs in both PD and DLB brains and calpain-cleaved fragments of $\alpha$-Syn colocalized with activated calpain. These data suggest that calpain I may be the molecular switch that turns on the aggregating properties of $\alpha$-Syn, providing a general mechanism for the initiation and evolution of LB formation in various $\alpha$-synucleinopathies.

\section{Materials and Methods}

\section{Cell-Free Assay}

A cell-free system was used consisting of human recombinant $\alpha$-synuclein ( $\alpha$-Syn) and purified calpain I from erythrocytes (both from Calbiochem, La Jolla, CA). Recombinant $\alpha$-Syn $(20 \mu \mathrm{g})$ was incubated with calpain I (2 $\mathrm{U})$ in a buffer containing $40 \mathrm{mmol} / \mathrm{L}$ HEPES (pH 7.2) and $5 \mathrm{mmol} / \mathrm{L}$ dithiothreitol at $37^{\circ} \mathrm{C}$. Reactions were initiated by the addition of calcium ( $1 \mathrm{mmol} / \mathrm{L}$ final). To stop the proteolysis, aliquots were removed from the reaction mixture and added to $5 \times$ sample buffer (Pierce, Rockford, $\mathrm{IL}$ ) at various times points, heated in a boiling water bath, and stored at $-20^{\circ} \mathrm{C}$ until used for either N-terminal sequencing or Western blot analysis. For N-terminal sequencing experiments, a total of $10 \mu \mathrm{g}$ of recombinant $\alpha$-Syn cleaved by calpain I was loaded in each well and separated using $15 \%$ sodium dodecyl sulfate-polyacrylamide gel electrophoresis gels. Gels were transferred electrophoretically to a polyvinylidene difluoride filter and stained with Coomassie blue to visualize bands. Potential low-molecular weight bands of interest were excised, and $\mathrm{N}$-terminal protein sequencing was accomplished (Midwest Analytical, Inc., St. Louis, MO). For circular dichroism (CD) and analytical ultracentrifugation (AUC) experiments, cell-free digestion was performed as described above, and samples were kept on ice until aliquots were removed for analysis.

\section{$C D$ Analysis}

Digestion of $\alpha$-Syn by calpain I was performed as described above in $20 \mathrm{mmol} / \mathrm{L}$ Tris buffer, $\mathrm{pH} 7.5$, containing $100 \mathrm{mmol} / \mathrm{L} \mathrm{NaF}$, for 30 minutes at $37^{\circ} \mathrm{C}$. Aliquots containing concentrations of $\alpha$-Syn $(0.2 \mathrm{mg} / \mathrm{ml})$ or calpain I $(0.15 \mathrm{mg} / \mathrm{ml})$, or samples containing $\alpha$-Syn and calpain I were added to $1-\mathrm{mm}$ path-length supracil quartz $\mathrm{cu}$ vettes (Hellma, Müllheim, Germany). CD spectra were recorded using a Jasco-810 spectropolarimeter (Jasco, Easton, $\mathrm{MD}$ ) at $20^{\circ} \mathrm{C}$ in triplicate using a step size of $1 \mathrm{~nm}$. Solvent blanks and spectra were collected from 190 to $250 \mathrm{~nm}$ and averaged, correcting for the buffer spectrum. Calpain I spectrum was subtracted from calpain plus $\alpha$-Syn mixture to generate the $\alpha$-Syn spectrum.

\section{AUC Analysis}

$\alpha$-Syn (1 mg/ml) was incubated with calpain I $(1.5 \mathrm{mg} / \mathrm{ml})$ for 30 minutes at $37^{\circ} \mathrm{C}$, and samples were placed on ice. Aliquots were used to determine sedimentation velocity coefficients using a Beckman Coulter XL-I analytical ultracentrifuge with an An-60 Ti rotor spun at $30,000 \mathrm{rpm}$ at $20^{\circ} \mathrm{C}$ for 4 hours (Beckman Coulter, Fullerton, CA). Radial scans were recorded measuring the absorbance of the samples at $280 \mathrm{~nm}$. The sedimentation coefficient of each sedimenting boundary was determined using UltraScan Analysis Software version 7.3 from Borries Demeler (University of Texas Science Center, San Antonio, TX). Each analysis incorporated 30 scans, and the values for the density and viscosity of the buffer relative to water were 1.0038 and 1.0227, respectively. Fringe displacement was then plotted as a function of radial distance within the cell, allowing for the determination of percent molecular weight changes of $\alpha$-Syn after digestion by calpain I.

\section{Generation of Site-Directed Calpain-Cleaved $\alpha$-Syn Antibodies}

Evidence suggests that there are no consensus peptide motifs for cleavage by calpains, and instead, it is the conformational determinants of the substrate, rather than primary sequence motifs, that are responsible for substrate recognition by calpains. ${ }^{22}$ Therefore, we sought to determine experimentally the cleavage sites within $\alpha$-Syn after incubation with calpain I. To identify potential calpain cleavage sites within $\alpha$-Syn, low-molecular weight bands were excised from polyvinylidene difluoride filters, and $\mathrm{N}$-terminal sequencing was performed. After digestion by calpain I, a consistent 9- to 10-kd fragment appeared. When sequenced, the N-terminal sequence of KAKEG was identified. KAKEG corresponds to the beginning amino acid sequence of a fragment of $\alpha$-Syn generated after cleavage between amino acids 9 and 10. Based on these preliminary results, we chose the peptide KAKEGVVAAGGGGGC for immunization in rabbits using the same strategy to generate similar antibodies developed in our laboratory. ${ }^{23}$ KAKEGVVAA represents the neoepitope region of the fragment that would be generated after cleavage of $\alpha$-Syn by calpain between amino acids 9 and 10. In addition, we used a string 
of glycine residues to increase the length of the peptide and to enhance the probability of an antigenic response. Affinity purification of antibodies was accomplished using a sulfolink column (Pierce) coupled with the peptide used as the immunogen (KAKEGVVAAGGGGGC). Hereafter, the affinity-purified antibody will be referred to as the $\alpha$-Syn calpaincleavage product antibody (CCP Ab). For this antibody, synthesis of peptides, injections of immunogens, and collection of antisera were contracted to Invitrogen Corporation (Carlsbad, CA). In addition, we also synthesized a sitedirected antibody to the $\mathrm{C}$ terminus after cleavage of $\alpha$-Syn between amino acids 122 and 123. A peptide was synthesized corresponding to the upstream neoepitope fragment that would be generated after cleavage of $\alpha$-Syn at this site (CPVDPDN), conjugated to keyhole limpet hemocyanin, and injected into rabbits as described above. After collection of antisera, the antibody was affinity purified. This antibody is referred to as the $\mathrm{C}$-terminal $\alpha$-SynCCP Ab. For this antibody, synthesis of peptides, injections of immunogens, and collection of antisera were contracted out to Bethyl Laboratories (Montgomery, TX). Figure 1 depicts the regions within $\alpha$-Syn to which synthetic peptides were synthesized to manufacture these two site-directed antibodies.

\section{Cell Culture}

Human neuroblastoma SH-SY5Y cells (American Type Culture Collection, Manassas, VA) were grown on 12-well plates to confluency (about $2 \times 10^{6}$ cells per well) with Dulbecco's modified Eagle's medium supplemented with $10 \%$ fetal bovine serum, $100 \mathrm{U} / \mathrm{ml}$ penicillin, and $100 \mu \mathrm{g} / \mathrm{ml}$ streptomycin and incubated at $37^{\circ} \mathrm{C}$ with $5 \% \mathrm{CO}_{2}$. The calcium ionophore A23187 (Sigma, St. Louis, MO) was prepared as a $4 \mathrm{mmol} / \mathrm{L}$ stock solution in dimethylsulfoxide. To activate calpain, SY5Y cells were incubated for various times in serum-free media supplemented with $12 \mathrm{mmol} / \mathrm{L}$ $\mathrm{CaCl}_{2}$ containing $3 \mu \mathrm{mol} / \mathrm{L}$ calcium ionophore A23187. Calpain I activation has been shown to be enhanced in SY5Y cells when treatment with the calcium ionophore is combined with an elevation of the extracellular calcium concentration. ${ }^{24}$ To block calpain activation, the calpain inhibitor III (EMD Biosciences, San Diego, CA) was prepared as a 10 $\mathrm{mmol} / \mathrm{L}$ stock solution in dimethylsulfoxide, diluted in serumfree media, and preincubated with cells at a final concentration of $10 \mu \mathrm{mol} / \mathrm{L}$. To permit adequate cellular loading, the calpain inhibitor was added 1 hour before the addition of A23187. After various treatments, SY5Y cell extracts were prepared by adding ice-cold lysis buffer $(50 \mathrm{mmol} / \mathrm{L}$ Tris$\mathrm{HCl}, 150 \mathrm{mmol} / \mathrm{L} \mathrm{NaCl}, 1 \% \mathrm{NP}-40,0.25 \%$ deoxycholate, and $1 \mathrm{mmol} / \mathrm{L}$ ethylene glycol bis( $\beta$-aminoethyl ether)$N, N, N^{\prime}, N^{\prime}$-tetraacetic acid, $\mathrm{pH} 7.4$, with protease inhibitor cocktail), followed by centrifugation and the addition of sample buffer.

\section{Preparation of Human Brain Lysates}

Case demographics are presented in Table 1. Frozen human temporal cortex tissue from age-matched control or DLB cases were homogenized in a Tris extraction buffer with $1 \%$ sodium dodecyl sulfate and protease in-

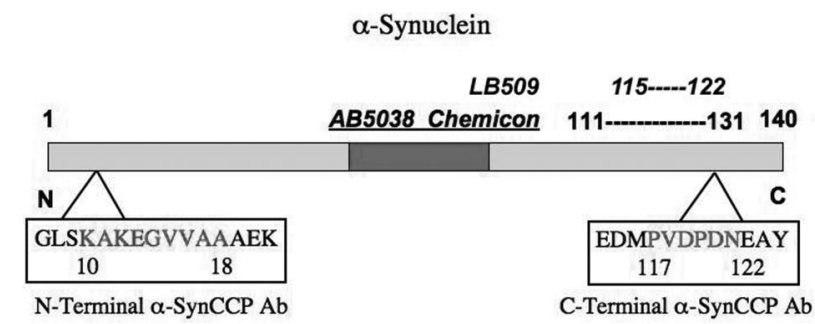

Figure 1. Peptide sequences used to generate site-directed calpain-cleavage Abs and locations of the epitopes for the full-length anti- $\alpha$-Syn Abs used in the present study. Sequences between amino acids 10 and 18 or 117 and 122 were used to synthesize peptides and generate polyclonal Abs as described in Materials and Methods. The N-terminal site was chosen based on sequence analysis after digestion of recombinant $\alpha$-Syn with calpain I, whereas the C-terminal site was chosen based on a previous report demonstrating the cleavage of $\alpha$-Syn between amino acids 122 and $123 .{ }^{19}$ Reported epitopes for the two full-length anti- $\alpha$-Syn Abs (LB509 and AB5038) used in this study are also shown.

hibitors (MP Biomedicals Inc., Solon, OH). After homogenization, samples were centrifuged for 1 hour at $4^{\circ} \mathrm{C}$ at $130,000 \times g$, and the supernatant was collected (representing the soluble fractions). Protein content was measured using the bicinchoninic acid method (Pierce Biotechnology Inc.), and equal protein amounts were analyzed by Western blot.

\section{Western Blot Analysis and Immunoprecipitation}

Human recombinant $\alpha$-Syn digested with calpain I, SY5Y cell extracts, or human brain lysates was processed for Western blot analysis. Briefly, proteins were separated by $12 \%$ sodium dodecyl sulfate-polyacrylamide gel electrophoresis and transferred to nitrocellulose. Membranes were incubated with $\alpha$-SynCCP Ab (1:100 to 1:500), and primary antibody was visualized using a goat anti-rabbit secondary antibody (1:5000; Jackson ImmunoResearch Laboratories, West Grove, PA), followed by enhanced chemiluminescence detection. Blots developed in the absence of secondary antibody were completely negative.

Immunoprecipitation (IP) experiments were performed using recombinant $\alpha$-Syn after digestion with calpain I. After incubation of $\alpha$-Syn $(20 \mu \mathrm{g})$ in the presence or absence of calpain I for 30 minutes, samples were incubated under nondenaturing conditions [phosphate-buffered saline (PBS) only] or under denaturing conditions (radioimmunoprecipitation assay buffer) together with 8 $\mu \mathrm{g}$ of the C-terminal $\alpha$-SynCCP Ab overnight at $4^{\circ} \mathrm{C}$. Samples were then incubated for 2 hours at room temperature with immobilized protein G (Pierce Biotechnology Inc.) to pull down immune complexes. Samples were centrifuged and washed three times in ice-cold PBS, and the supernatant was discarded. Pellets were solubilized with $5 \times$ sample buffer and boiled for 5 minutes before loading on sodium dodecyl sulfate-polyacrylamide gel electrophoresis gels. After transfer onto nitrocellulose and blocking, blots were incubated overnight with polyclonal FL anti- $\alpha$-Syn (AB5038; 1:1000). Bands were visualized using enchanced chemiluminescene detection system. 
Table 1. Case Demographics for Immunohistochemistry and Western Blot Analyses

\begin{tabular}{|c|c|c|c|c|}
\hline Case & $\begin{array}{c}\text { Neuropathological } \\
\text { diagnosis }\end{array}$ & Sex & Age (years) & PMI (hours) \\
\hline $1(\mathrm{IH})$ & DLB & M & 88 & 2.0 \\
\hline $2(\mathrm{IH})$ & DLB & M & 75 & 6.0 \\
\hline $3(\mathrm{IH})$ & DLB & M & 67 & 2.5 \\
\hline $4(\mathrm{IH})$ & DLB & M & 72 & 5.5 \\
\hline $5(\mathrm{IH})$ & DLB & $\mathrm{F}$ & 77 & 2.8 \\
\hline 6 (WB) & DLB/AD & $\mathrm{F}$ & 77 & 5.4 \\
\hline 7 (WB) & DLB & M & 85 & 4.9 \\
\hline 8 (WB) & DLB & M & 71 & 2.6 \\
\hline 9 (WB) & DLB & M & 70 & 3.6 \\
\hline 10 (WB) & DLB & M & 83 & 9.5 \\
\hline Mean & & & $76.5 \pm 6.93$ & $4.48 \pm 2.28$ \\
\hline $1(\mathrm{IH})$ & $\mathrm{PD} / \mathrm{AD}$ & $\mathrm{F}$ & 88 & 3.0 \\
\hline $2(\mathrm{IH})$ & PD & $\mathrm{F}$ & 86 & 13.5 \\
\hline $3(\mathrm{IH})$ & $\mathrm{PD} / \mathrm{AD}$ & M & 64 & 2.3 \\
\hline $4(\mathrm{IH})$ & $\mathrm{PD}$ & $M$ & 69 & 4.5 \\
\hline $5(\mathrm{IH})$ & PD & M & 71 & 3.5 \\
\hline Mean & & & $75.6 \pm 10.7$ & $5.36 \pm 4.62$ \\
\hline 1 (WB) & CTL & $\mathrm{F}$ & 73 & 4.0 \\
\hline 2 (WB) & CTL & M & 64 & 7.0 \\
\hline 3 (WB) & CTL & M & 77 & 6.5 \\
\hline 4 (WB) & CTL & $\mathrm{F}$ & 74 & 2.8 \\
\hline Mean & & & $72 \pm 5.59$ & $5.08 \pm 2.00$ \\
\hline
\end{tabular}

DLB cases 1 to 5 were used for IH analysis, whereas cases 6 to 10 and CTL cases were used for Western blot analysis (WB). PMI, postmortem interval; M, male; F, female; AD, Alzheimer's disease; CTL, age-matched control cases.

\section{Cerebral Ischemia Produced by Middle Cerebral Artery Occlusion}

C57BL/6 mice (20 to $23 \mathrm{~g}$ ) were subjected to middle cerebral artery occlusion (MCAO) as described previously. ${ }^{25}$ In brief, under anesthesia, mice were subjected to MCAO using an intraluminal filament for 1 hour. After 1 hour of MCAO, the filament was removed, and blood flow was restored for 24 hours, at which time animals were sacrificed. Mouse brains were perfused with 10\% formalin in PBS and then postfixed in 10\% formalin for 4 hours and cryoprotected overnight in phosphate buffer containing $30 \%$ sucrose at $4^{\circ} \mathrm{C}$. After fixation, brains were sectioned into $50-\mu \mathrm{m}$ free-floating sections to be processed by immunohistochemistry. Ischemic infarct areas were identified by Hoechst staining as described previously. ${ }^{25}$

\section{Human Subjects}

Autopsy brain tissue from the substantia nigra of five neuropathologically confirmed PD and 10 DLB cases was studied. Case demographics are presented in Table 1. Age at death was not significantly different between PD (mean $76 \pm 10$ ), DLB (mean $77 \pm 7$ ), and controls (mean $72 \pm 6$ ). Autopsy brain tissues used in this study were generously provided by the Institute for Brain Aging and Dementia Tissue Repositories at the University of California (Irvine, CA).

\section{Immunohistochemistry and Immunofluorescence of Human Postmortem Brain Sections}

Free-floating 40- $\mu \mathrm{m}$-thick serial sections were used for immunohistochemical and immunofluorescence studies as previously described. ${ }^{26}$ Antibody dilutions were as follows: $\alpha$-SynCCP, 1:100; C-terminal $\alpha$-SynCCP, $1: 100$; full-length polyclonal anti- $\alpha$-Syn AB5038, 1:1000 (Chemicon International, Temecula, CA); mouse full-length mAb anti- $\alpha$-Syn LB509, 1:200 (Zymed Labs, San Francisco, CA); and anti-calpain-1, C-terminal, human, 1:100 (EMD Biosciences). Antigen visualization was determined using avidin-biotin-peroxidase complex (ABC Elite immunoperoxidase kit; Vector Labs, Burlingame, CA), followed by 3,3'-diaminobenzidine (DAB) substrate with nickel chloride, which generates a black product, or NovaRed, which generates an orange product (Vector Labs). For immunofluorescence studies, antigen visualization was accomplished using an Alexa Fluor 488-labeled tyramide (green, excitation/emission $=495 / 519$ ) or streptavidin Alexa Fluor 555 (red, excitation/emission = 555/565), both from Invitrogen (Carlsbad, CA).

\section{Quantification}

Substantia nigra from five neuropathologically confirmed PD and DLB were examined by bright-field immunohistochemical microscopy after labeling with either $\alpha$-SynCCP Ab or full-length mAb anti- $\alpha$-Syn (LB509) as described above. The full-length anti- $\alpha$-Syn mAb was used to identify Lewy bodies in brain sections because fulllength $\alpha$-Syn is the most sensitive marker known for Lewy bodies. ${ }^{8}$ To ensure that cross-reactivity to reagents was not a factor in double-labeling experiments, experiments were replicated with antibodies in reverse without consequence. The total number of Lewy bodies and neurites with and without $\alpha$-SynCCP labeling was counted in each of the five cases. Subsequently, the number of Lewy bodies and neurites containing $\alpha$-SynCCP was counted separately to determine the relative percentage of Lewy 
bodies containing calpain-cleaved $\alpha$-Syn. Raw counts were summed and analyzed using a Pearson rank correlation coefficient (Microsoft Excel, Redmond, WA) to examine a possible relationship between these two variables. Data were plotted and fitted using a nonlinear regression to the second power.

\section{Immunohistochemistry of Transgenic Mouse and Drosophila Tissue Sections}

PD A30P mice brains were processed for immunohistochemical analysis as previously described. ${ }^{27}$ In brief, after fixation of brains, 50- $\mu \mathrm{m}$ coronal free-floating sections were prepared using a vibratome and stored in sodium azide/PBS buffer at $4^{\circ} \mathrm{C}$. Age- and strainmatched nontransgenic control mice brains were processed in a similar fashion.

Two additional Tg PD mouse models including one line expressing human wild-type $\alpha$-Syn under the plateletderived growth factor (PDGF) promoter ${ }^{28}$ and one line expressing wild-type human $\alpha$-Syn under the Thy- 1 promoter $^{29}$ were examined by $\mathrm{IH}$ and Western blot analysis using the C-terminal $\alpha$-SynCCP Ab. In this case, purified antibody was shipped to the laboratory of Dr. Eliezer Masliah (University of California, San Diego, CA), and experiments were independently performed by his transgenic mouse team. Immunoreactivity of the C-terminal $\alpha$-SynCCP Ab was also assessed in a transgenic Drosophila model of PD as previously described.$^{30}$ In brief, 20-day-old adult flies were fixed in formalin and embedded in paraffin, and sections were processed using the avidin-biotin-peroxidase system and DAB to visualize staining. Sections were counterstained with hematoxylin. Purified C-terminal antibody was shipped to the laboratory of Dr. Mel Feany (Harvard Medical School, Boston, MA) where the staining was performed.

\section{Results}

\section{Calpain Cleavage of $\alpha$-Syn Results in} Aggregation and Adoption to a $\beta$-Sheet Configuration

To examine a potential role for calpain I in the proteolytic processing of $\alpha$-Syn, cell-free assays were undertaken using soluble human recombinant $\alpha$-Syn and purified calpain I. $\alpha$-Syn was efficiently digested by calpain I, leading to the disappearance of full-length $\alpha$-Syn (14 kd) and formation of both low- and high-molecular weight bands (Figure 2A). These results confirm a previous report indicating that $\alpha$-Syn is a suitable substrate for calpain I cleavage. ${ }^{19}$ Because truncation of $\alpha$-Syn has been shown to enhance its self-aggregation and lead to the adoption of a $\beta$-sheet structure, ${ }^{12,13,31}$ we examined whether similar changes occur to calpain-cleaved $\alpha$-Syn by using $A \cup C$ and $C D$ analyses. As shown in Figure 2B, digestion of $\alpha$-Syn by calpain I led to the formation of high-molecular weight species as determined by AUC.

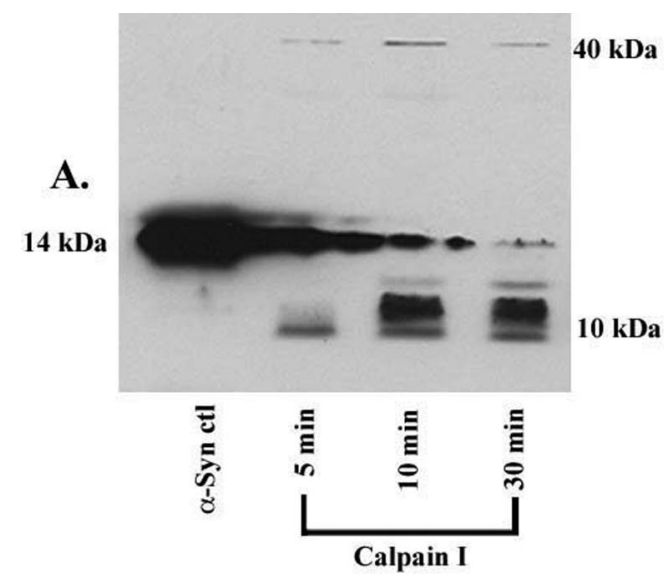

B.
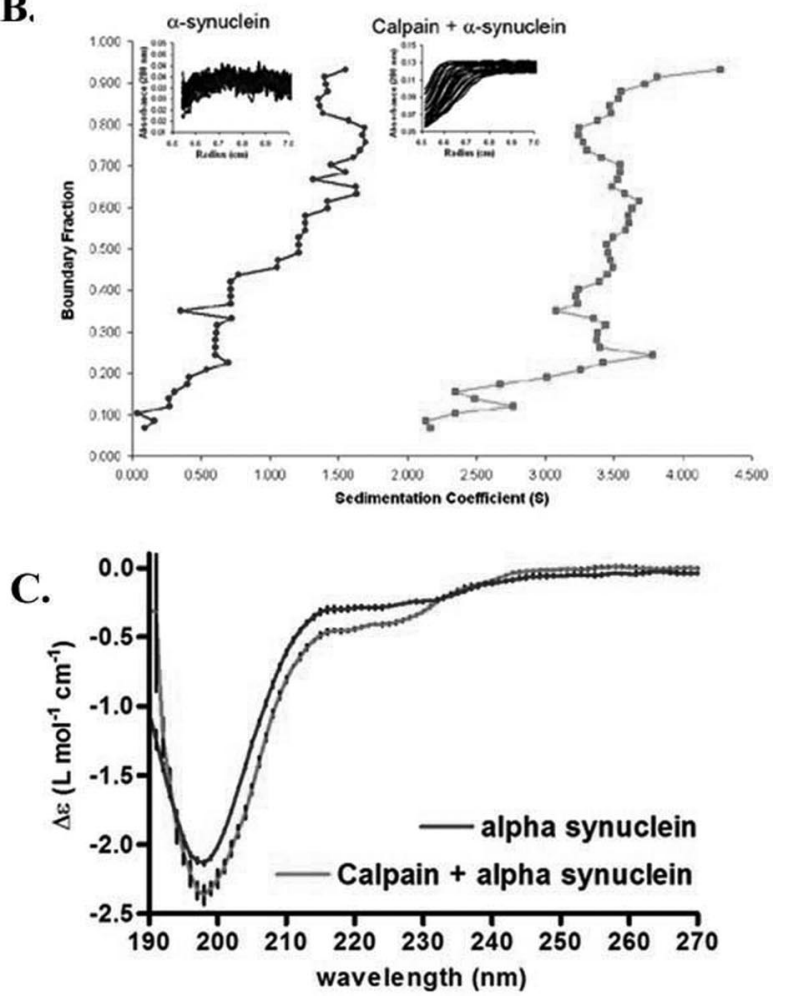

Figure 2. Calpain cleavage of $\alpha$-synuclein results in aggregation and adoption of a $\beta$-sheet configuration. A: After incubation of $\alpha$-Syn with calpain I for various periods of time in a cell-free assay, samples were subjected to gel electrophoresis, transferred to nitrocellulose filters, and probed with an antibody to FL $\alpha$-Syn (AB5038). Over time, the appearance of low- and high-molecular weight bands were evident in addition to the disappearance of FL $\alpha$-Syn ( $14 \mathrm{kd}$ ). B: Analytical ultracentrifugation analysis after incubation of $\alpha$-Syn alone (line on the left) or after digestion with calpain I (line on the right) for 30 minutes indicated the presence of high-molecular weight species. Insets represent the 30 raw data scans used for data analysis. C: CD spectra after incubation of $\alpha$-Syn with calpain I indicated a change in structure from random coil to a $\beta$-sheet configuration. CD spectra of $\alpha$-Syn alone (top line) and mixture of $\alpha$-Syn incubated with calpain I with the calpain spectrum subtracted (bottom line).

Sedimentation analysis revealed that $96 \pm 1.8 \%$ of the molecular species present after digestion of $\alpha$-Syn by calpain I exhibited a molecular mass of $40 \mathrm{kd}$. In addition, $\mathrm{CD}$ analysis indicated that calpain-cleaved $\alpha$-Syn resulted in a change in secondary structure that was consistent with a $\beta$-sheet conformation (Figure $2 \mathrm{C}$ ). CD results obtained were similar to those published in a 

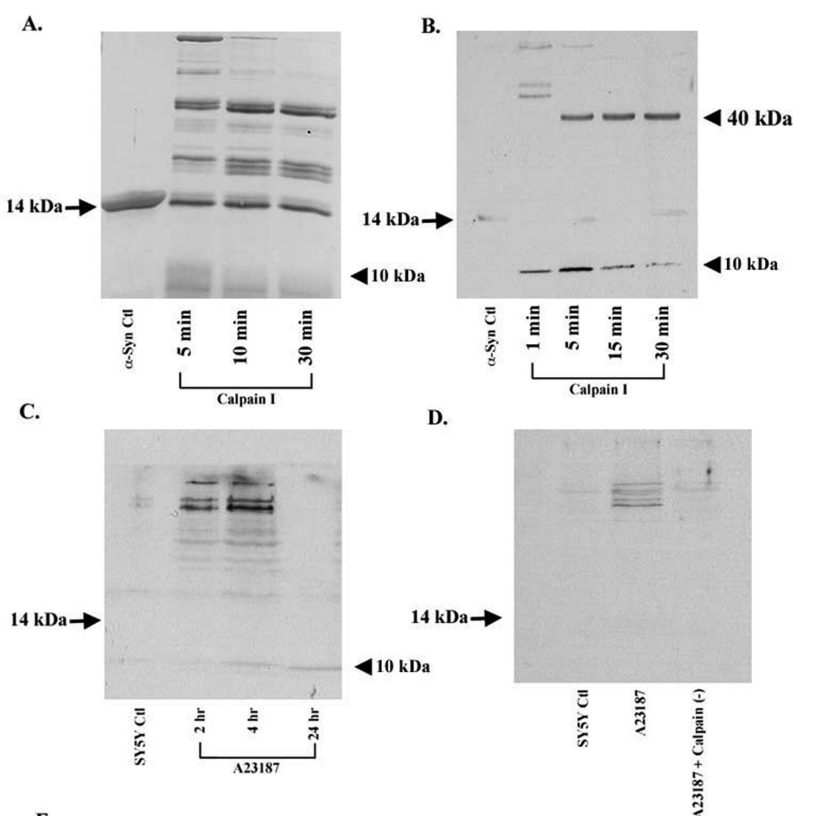

E.

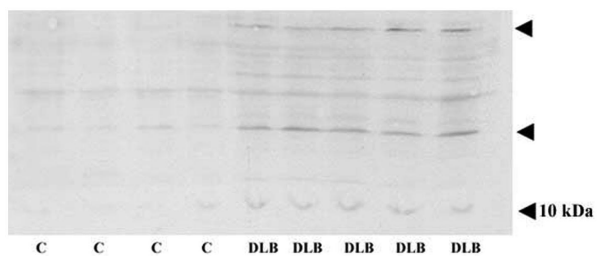

Figure 3. Calpain cleavage of $\alpha$-Syn results in aggregation and formation of high-molecular weight species. A: After incubation of $\alpha$-Syn with calpain I for various periods of time in a cell-free assay, samples were subjected to gel electrophoresis, transferred to polyvinylidene difluoride filters, and stained with Coomassie blue. Over time, the appearance of low- and high-molecular weight bands were evident in addition to the disappearance of full-length $\alpha$-Syn (14 kd). B: Western blot analysis reveals the presence of high-molecular weight bands after digestion of $\alpha$-Syn with calpain I in a cell-free system. $\alpha$-Syn was incubated with calpain I for the indicated times, and samples representing the soluble fractions were immunoblotted using the $\alpha$-SynCCP $\mathrm{Ab}$. The arrowhead indicates the immunoreactivity of the $\alpha$-SynCCP Ab with a 10-kd fragment of $\alpha$-Syn. C: Western blot analysis using the $\alpha$-SynCCP Ab demonstrated the presence of calpain-cleaved aggregates of $\alpha$-Syn after treatment of SY5Y neuroblastoma cells with the calcium ionophore A23187 (C, lanes marked 2 and 4 hours), which were prevented after pretreatment of cells with a calpain I inhibitor (D, far right lane). E: Detection of numerous high-molecular weight calpain-cleavage aggregates of $\alpha$-Syn in the DLB brain by Western blot analysis. Human brain lysates from age-matched controls or DLB cases were probed with the $\alpha$-SynCCP antibody. Arrowheads above 10 $\mathrm{kd}$ indicate the presence of bands between 30 and $80 \mathrm{kd}$.

previous study examining the secondary structure changes after expression of truncated $\alpha$-Syn species in Escherichia coli. ${ }^{31}$

\section{Calpain Cleavage of $\alpha$-Syn Leads to the Formation of High-Molecular Weight Species}

To determine whether calpain cleaves $\alpha$-Syn in the PD or DLB brain, we designed a site-directed calpain-cleavage antibody that specifically detects cleaved but not fulllength (FL) $\alpha$-Syn. To accomplish this, N-terminal sequencing was performed on the 10-kd band that formed after digestion of $\alpha$-Syn by calpain I (arrowhead in Figure $3 \mathrm{~A}$, lane marked 5 minutes). This sequence was used to synthesize a corresponding peptide that could be used to generate polyclonal antibodies (for details, see Materials and Methods). After affinity purification of this antibody, hereafter termed the $\alpha$-Syn CCP Ab, specificity was determined by Western blot analysis. The $\alpha$-SynCCP Ab recognized the predicted 10-kd fragment of $\alpha$-Syn but did not detect FL $\alpha$-Syn (14 kd) (Figure 3B). In addition to recognizing the predicted $10-\mathrm{kd}$ calpain-cleaved fragment of $\alpha$-Syn, the $\alpha$-SynCCP Ab immunolabeled a prominent band at $\sim 40 \mathrm{kd}$ (Figure 3B), which corresponds to the exact size of the species calculated after AUC analysis (Figure 2B). The $\alpha$-SynCCP Ab identified high molecular calpain-cleaved aggregates of $\alpha$-Syn with no immunoreactivity to $\mathrm{FL} \alpha$-Syn in an in vitro model system (Figure 3, C and D) as well as in DLB brain extracts (Figure 3E). The $\alpha$-SynCCP Ab also detected the 10-kd cleavage fragment of $\alpha$-Syn in all DLB subjects examined (Figure 3E).

\section{Detection of Calpain-Cleaved $\alpha$-Syn in Vivo}

To confirm further the specificity of the $\alpha$-SynCCP Ab and to demonstrate that calpain cleavage of $\alpha$-Syn does not represent an entirely artificial phenomenon, experiments were undertaken using an animal model of ischemia/ reperfusion injury. C57BL/6 mice were subjected to MCAO as described previously. ${ }^{25}$ This model has been previously used to demonstrate calpain activation and cleavage of cellular proteins ${ }^{25}$ and has the advantage that the ischemic infarct is confined to one side of the brain, leaving the other side intact and damage-free, which allows for an internal control. Because the protein sequence of $\alpha$-Syn in the region used to generate the $\alpha$-SynCCP Ab is conserved between murine and human sequences (Basic Local Alignment Search Tool alignment; data not shown), we anticipated the $\alpha$-SynCCP Ab would recognize murine calpain-cleaved $\alpha$-Syn. We performed IH/IF on brain sections from MCAO mice using the $\alpha$-SynCCP Ab and detected calpain-cleaved $\alpha$-Syn only in the ischemic infarct areas (Figure 4, B and D). Labeled neurons appeared shrunken and damaged. No staining was observed on the contralateral side of the brain (Figure 4, A and C) nor in controls or shams (data not shown). These data suggest that calpain cleavage of $\alpha$-Syn occurs in vivo under conditions known to activate calpain I and can be specifically detected using our $\alpha$-SynCCP Ab.

To test whether the $\alpha$-SynCCP Ab could detect calpain-cleaved $\alpha$-Syn in an animal model of PD, application of the $\alpha$-SynCCP Ab was performed on fixed sections using Tg mice overexpressing mutant $\alpha$-Syn. These mice overexpress human $\alpha$-Syn harboring the A30P mutation (line Tg5093) under the control of the prion protein promoter. ${ }^{27}$ Heterozygous mice develop severe motor dysfunction characterized by rigidity, dystonia, gait impairment, and tremor after high expression of the transgene in numerous areas of the brain. ${ }^{27}$ Figure 5 depicts results after application of the $\alpha$-SynCCP Ab in age-matched non-Tg controls or from 4- and 12-month-old heterozygous PD mice. Interestingly, we detected strong punctate staining localized in clusters within the hippocampus of 

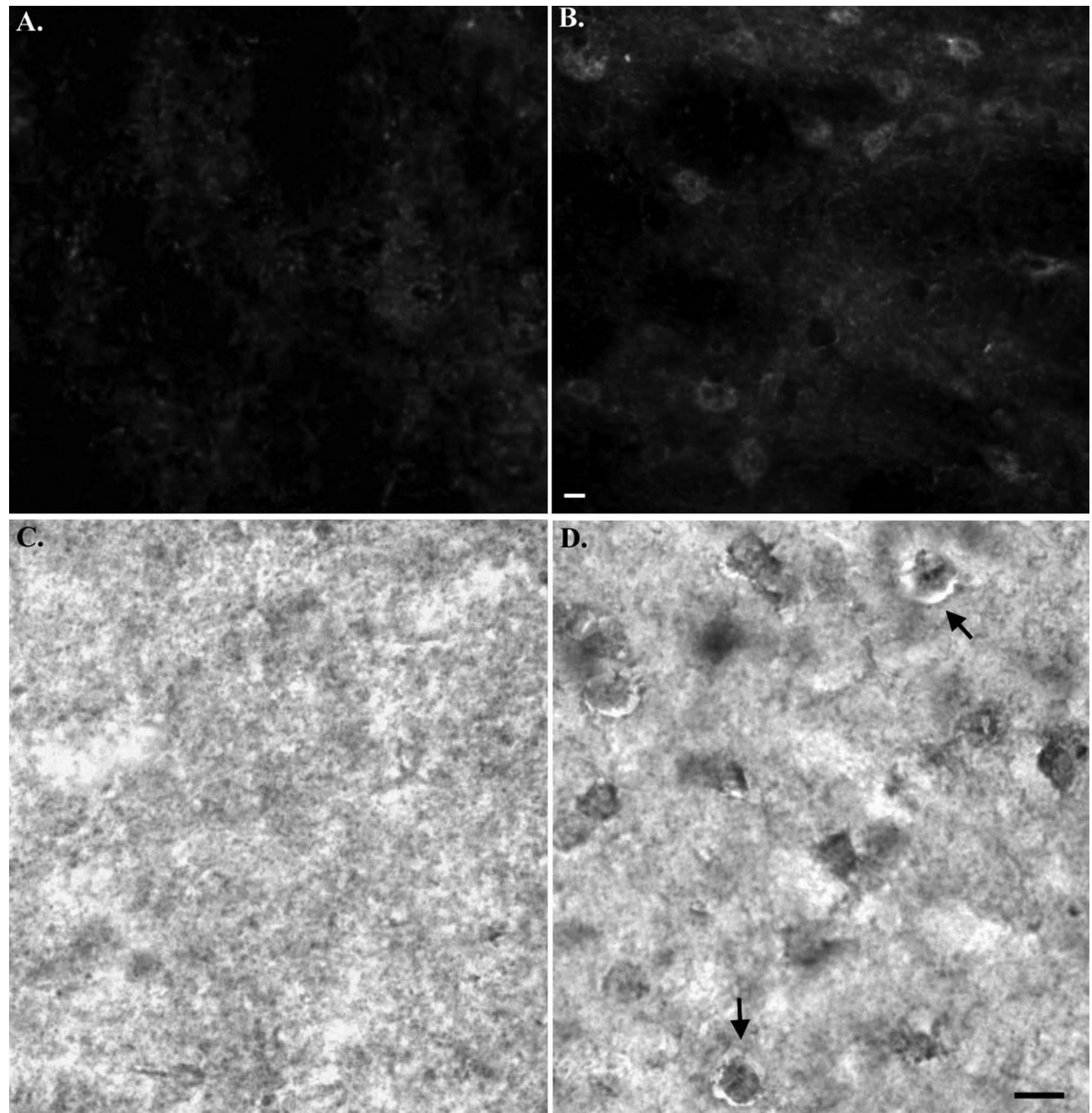

Figure 4. Detection of calpain-cleaved $\alpha$-Syn in an animal model of cerebral ischemia. Mice were subjected to 1 hour of MCAO, followed by reperfusion for 24 hours. Sections at $50 \mu \mathrm{m}$ were subjected to either IF or IH analysis using the $\alpha$-SynCCP Ab (1:100) to detect calpain-cleaved $\alpha$-Syn. Staining of shrunken, damaged neurons in the cortex of MCAO mice was evident only in ischemic infarct areas ( $\mathbf{B}$, fluorescence, and $\mathbf{D}$, bright-field DAB labeling) and was not evident on the contralateral side of the brain (A and $\mathbf{C})$. Scale bars $=10 \mu \mathrm{m}$.

aged non-Tg mice sections (Figure 5A). This staining most likely represents so called "Wirak bodies" that are typical age-associated inclusions associated with C57BL/6 mice. ${ }^{32}$ In the cortex, however, tissue sections from non-Tg age-matched control mice were completely devoid of any labeling (Figure 5B). In 4-month-old asymptomatic Tg PD mice, little staining was observed in the cortex (Figure $5 \mathrm{C}$ ) or any other brain regions including the hippocampus (data not shown). In contrast, strong neuronal staining in the cortex was seen in 12month-old Tg PD mice (Figure 5D). Staining of neurons was also observed in a subset of neurons in the hippocampus (data not shown).

\section{Calpain Cleavage of $\alpha$-Syn Is Evident in PD and DLB Brains}

To determine in situ whether calpain cleaves $\alpha$-Syn in PD or DLB, immunohistochemical $(\mathrm{IH})$ and immunofluorescence (IF) experiments were undertaken using the $\alpha$-SynCCP Ab. Calpain-cleaved $\alpha$-Syn was evident within Lewy 

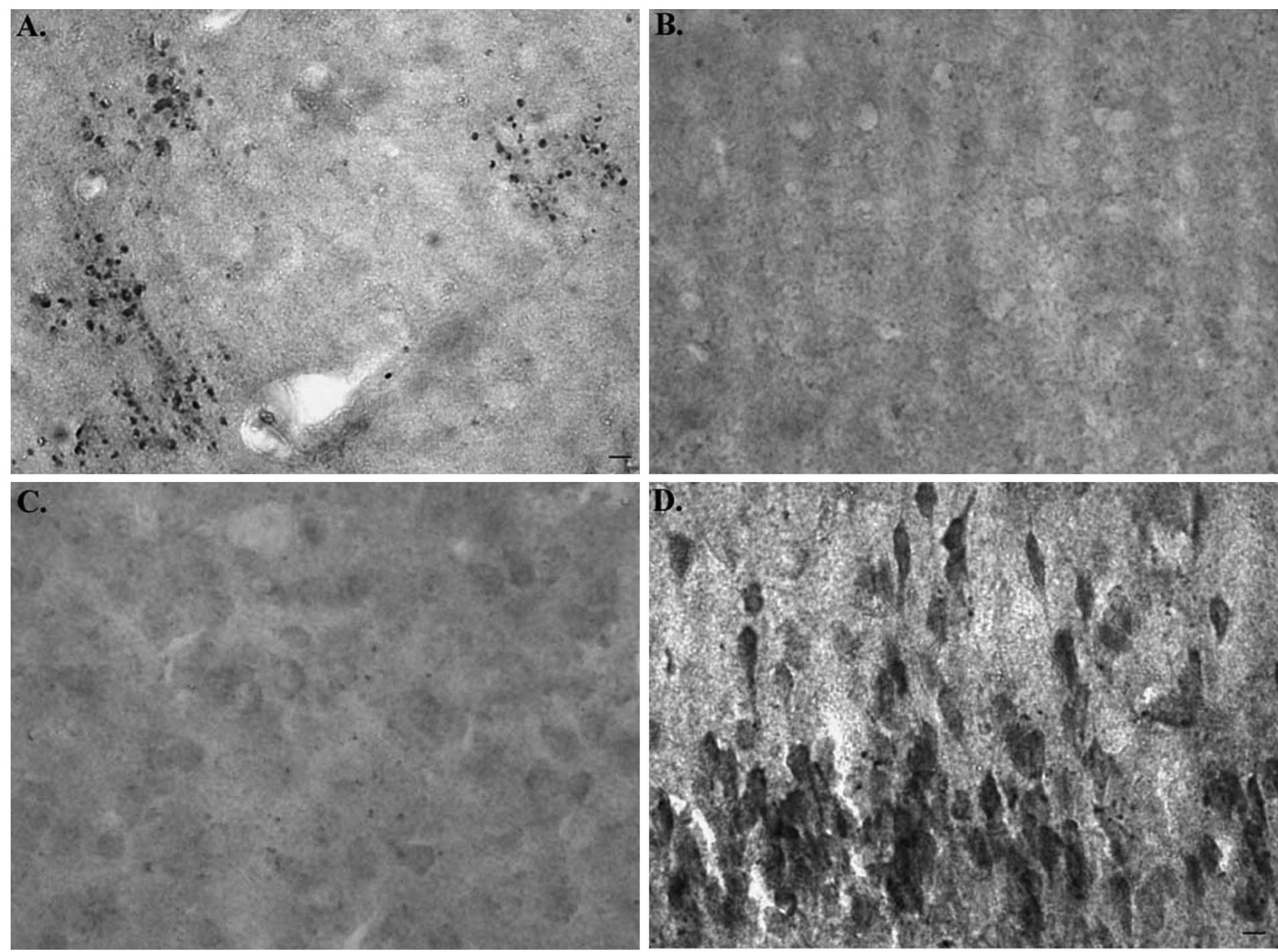

Figure 5. Detection of calpain-cleaved $\alpha$-Syn in a transgenic mouse model of PD. Fixed-tissue brain sections from age-matched non-Tg controls in the hippocamus (A) or cortex (B) immunolabeled with the $\alpha$-SynCCP Ab (1:100). C and D: Cortical staining from 4-month-old asymptomatic PD Tg mice (C) or 12-month-old PD Tg mice (D) was immunolabeled with the $\alpha$-SynCCP Ab (1:100). Scale bars $=10 \mu \mathrm{m}$.

bodies and Lewy neurites in the substantia nigra of both DLB and PD brains (Figure 6). No neuritic labeling was evident, nor did we observe labeling of axonal spheroids after application of the $\alpha$-SynCCP Ab. Two consistent features were apparent after labeling with the $\alpha$-SynCCP Ab. First, calpain-cleaved $\alpha$-Syn seemed to localize primarily within the core of Lewy bodies (Figure 6, B and $\mathrm{I}-\mathrm{N})$. Second, we often observed staining that appeared granular and sheet-like (Figure 6, C and E), suggesting that calpain-cleaved $\alpha$-Syn is in an aggregated configuration. Importantly, staining with the $\alpha$-SynCCP Ab was completely prevented after preadsorption with free peptide (data not shown).

Quantification was performed to determine a possible relationship between calpain-cleaved $\alpha$-Syn and the number of Lewy body structures in DLB and PD. Both LBs and neurites with and without calpain-cleaved $\alpha$-Syn products were quantified. There was a positive relationship between these two variables; as the number of LB structures increased, so did the appearance of calpaincleaved $\alpha$-Syn (Figure 6, G and $\mathrm{H}$ ). In this regard, we found the presence of calpain-cleaved $\alpha$-Syn in $70 \pm$ $8.9 \%$ of the total number of LBs and neurites identified in DLB (799 of 1131). In PD, $90 \pm 3.4 \%$ of the total number of LBs and neurites identified had the presence of calpain-cleaved $\alpha$-Syn (542 of 603). It is noteworthy that we also detected calpain-cleaved $\alpha$-Syn in nonhyaline LBs in the cortex of DLB subjects (Supplemental Figure 1, see http://ajp.amjpathol.org). In addition, widespread staining within degenerating astrocytes was also observed in cortical white matter of DLB subjects (Supplemental Figure 1, see http://ajp.amjpathol.org).

We next examined whether calpain-cleaved $\alpha$-Syn colocalized with the enzyme calpain I in PD and DLB brains. As shown in Figure 6, O-T, we detected activated calpain I surrounding Lewy bodies containing calpain-cleaved $\alpha-S y n$.

\section{Evidence for C-Terminal Truncation of $\alpha$-Syn in the DLB Brain}

Because numerous studies have documented the presence of C-terminal truncated species of $\alpha$-Syn in PD and DLB, ${ }^{10-12,33}$ we examined whether calpain may mediate this proteolytic role. In vitro, our results suggested that a major fragment generated after cleavage of $\alpha$-Syn by calpain I was approximately $10 \mathrm{kd}$ in size (Figures 1 and 


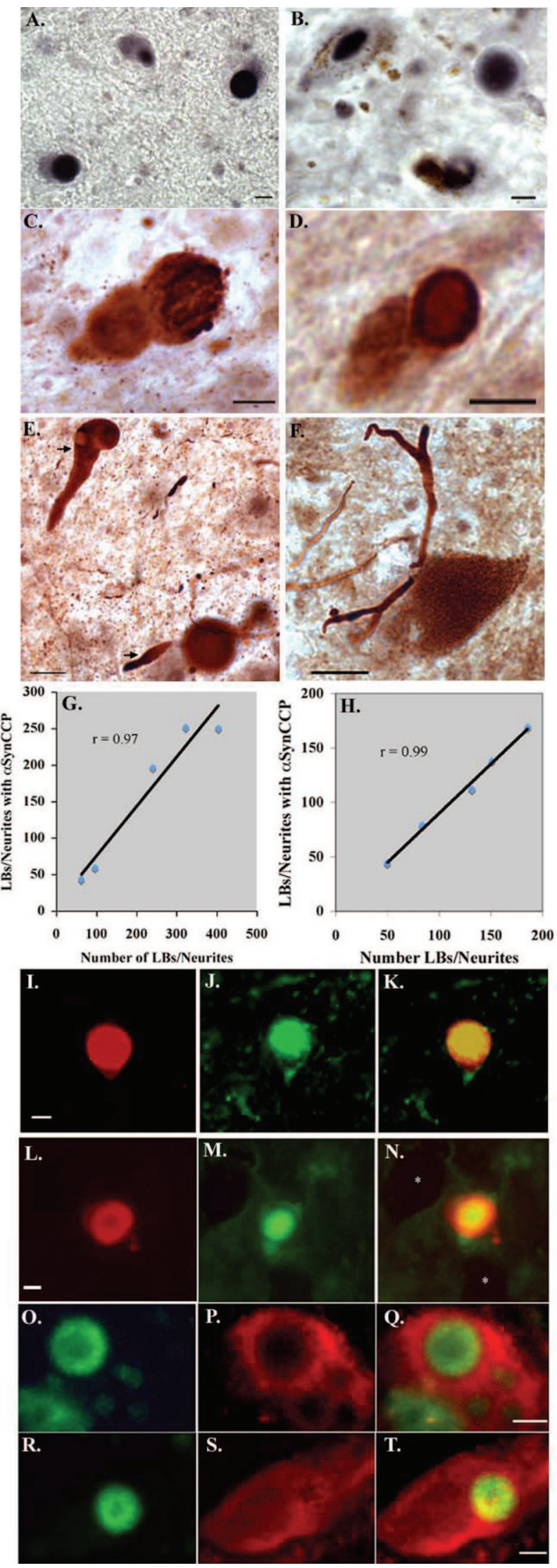

2). FL $\alpha$-Syn has a molecular mass of $14 \mathrm{kd}$; this suggests an additional cleavage event near the $C$ terminus of $\alpha$-Syn. Based on this and a previous study, ${ }^{19}$ we hypothesized that calpain I also cleaves $\alpha$-Syn between amino acids 122 and 123. We synthesized a peptide corresponding to the upstream neoepitope fragment that would be generated after cleavage of $\alpha$-Syn at this site (PVDPDN) and generated C-terminal $\alpha$-SynCCP Abs (see Materials and Methods for details). Figure 7 depicts the results after application of this antibody showing that it immunolabels the predicted 10-kd fragment of $\alpha$-Syn (Figure 7A). This supports the conclusion that calpain I is able to cleave $\alpha$-Syn both at the $\mathrm{N}$ - and C-terminal ends of $\alpha$-Syn and that these cleavage events happen simultaneously. Unlike the N-terminal $\alpha$-SynCCP Ab, the Cterminal $\alpha$-SynCCP Ab seemed to immunolabel FL $\alpha$-Syn under denaturing conditions (Figure 7A). However, it should be noted that ample levels of FL $\alpha$-Syn were still present in all lanes even after digestion with calpain I (Figure 3A), yet there was no detection of FL $\alpha$-Syn under these conditions. Application of this antibody by brightfield microscopy or by immunofluorescence of represented DLB cases indicated a similar staining pattern as with the N-terminal $\alpha$-SynCCP antibody; namely, a staining pattern that was found within Lewy structures and was fibrillary in its appearance (Figure 7, B and C). Double-labeling experiments confirmed the colocalization of C-terminal $\alpha$-SynCCP labeling with a marker for LBs (Figure 7, D-K). Figure 7D (left) was overexposed purposely to better see the separation of the two colors. Similar results were obtained in PD cases (data not shown).

To evaluate further the specificity of the C-terminal $\alpha$-SynCCP Ab, IH and Western blot experiments were performed using several Tg mouse models of PD. IH experiments provided evidence for calpain-cleaved $\alpha$-Syn in two unique Tg mouse models of PD, including one line expressing human wild-type $\alpha$-Syn under the PDGF promoter ${ }^{28}$ and one line expressing human wildtype $\alpha$-Syn under the Thy- 1 promoter. ${ }^{29}$ In this case, labeling within neurons was evident in the neocortex for PDGF $\alpha$-Syn Tg mice and Thy- $1 \alpha$-Syn Tg mice, respectively (Figure $8, \mathrm{~B}$ and $\mathrm{C}$ ), and staining was comparable

Figure 6. Detection of calpain-cleaved species of $\alpha$-Syn in PD and DLB. A and $\mathbf{B}$ : Representative immunohistochemical single-label staining in the substantia nigra of a DLB (A) and PD (B) case after application of the $\alpha$-SynCCP $\mathrm{Ab}$ demonstrates the presence of calpain-cleaved $\alpha$-Syn within Lewy bodies. C and D: Double-label immunohistochemical analysis with $\alpha$-SynCCP Ab (black) together with a marker for Lewy bodies (LB509, orange) reveals colocalization in Lewy bodies from a representative DLB (C) or PD (D) case. Colocalization was also observed in Lewy neurites in DLB (E, arrows) or PD (F) cases. $\mathbf{G}$ and $\mathbf{H}$ : Graphical representations depicting the relationship between calpain-cleaved $\alpha$-Syn and the number of LBs/neurites in five different DLB (left) or PD (right) cases. Data indicate a high degree of association between the total number of LBs/neurites and the presence of calpain-cleaved $\alpha$-Syn. I-N: Double-label immunofluorescence images for $\alpha$-SynCCP (green) and an antibody to full-length $\alpha$-Syn (red) confirmed the colocalization of calpain-cleaved $\alpha$-Syn within Lewy bodies in a representative DLB (I-K) or PD $(\mathbf{L}-\mathbf{N})$ case. Yellow/orange coloring in $\mathbf{K}$ and $\mathbf{N}$ indicate areas where markers are overlapping. O-T: Double-label immunofluorescence images for $\alpha$-SynCCP (green) and calpain I (red) demonstrating the presence of active fragments of the enzyme surrounding Lewy bodies containing calpain-cleaved $\alpha$-Syn. $\mathbf{O}-\mathbf{Q}$ and $\mathbf{R}-\mathbf{T}$ : Representative staining of a DLB or PD case, respectively. Yellow/orange coloring in $\mathbf{Q}$ and $\mathbf{T}$ indicate areas where markers are overlapping. Asterisks in $\mathbf{N}$ denote regions containing neuromelanin. All scale bars $=10 \mu \mathrm{m}$. 

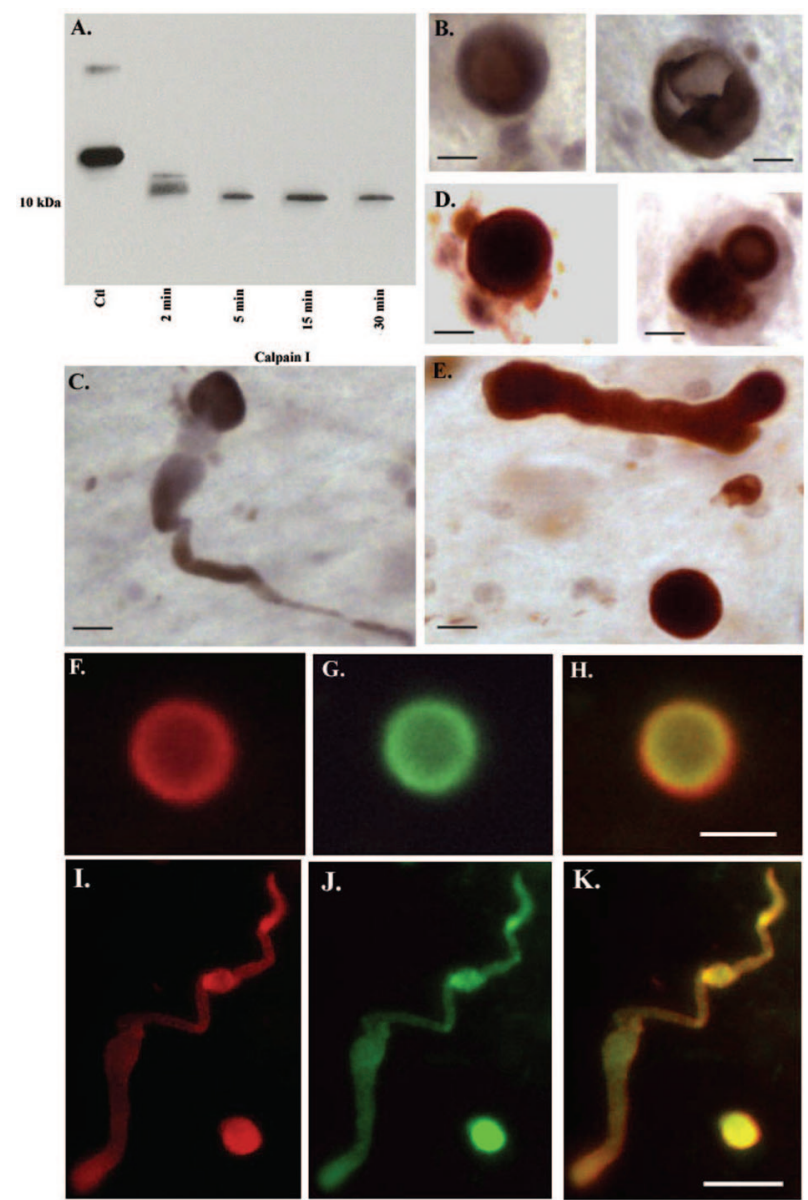

Figure 7. Evidence for C-terminal truncation of $\alpha$-Syn in the DLB brain. A and B: Characterization of the C-terminal $\alpha$-SynCCP Ab by Western blot analysis. Recombinant human $\alpha$-Syn $(20 \mu \mathrm{g})$ was incubated for various periods of time with calpain I ( $2 \mathrm{U})$, separated by $15 \%$ sodium dodecyl sulfate-polyacrylamide gel electrophoresis gels, transferred to nitrocellulose, and probed with an antibody directed toward a predicted C-terminal calpaincleavage site (PVDPDN) of $\alpha$-Syn (A). The antibody immunolabeled the predicted 10-kd fragment of $\alpha$-Syn. B: Representative immunohistochemical single-label staining of LBs in the substantia nigra of two DLB cases after application of the C-terminal $\alpha$-SynCCP Ab. C: Identical to $\mathbf{B}$, showing labeling with a single Lewy neurite. $\mathbf{D}$ and E: Double-label immunohistochemical analysis in a representative DLB case showing localization of the C-terminal $\alpha$-SynCCP Ab within LBs and neurites (nickel DAB), which colocalized with a marker for LBs (Nova Red). F-K: Immunofluorescence with the C-terminal $\alpha$-SynCCP Ab shown in green ( $\mathbf{G}$ and $\mathbf{J}$ ), FL $\alpha$-Syn Ab (LB509) in red ( $\mathbf{F}$ and $\mathbf{I})$, and the overlap image $(\mathbf{H}$ and $\mathbf{K})$. All scale bars $=10 \mu \mathrm{m}$

with a FL $\alpha$-Syn Ab (Figure 8, E and F). No staining was observed in non-Tg age-matched control mice after application of the C-terminal $\alpha$-SynCCP Ab (Figure 8A). A similar staining profile was observed in the hippocampus (data not shown). We were also able to document immunoreactivity of the C-terminal $\mathrm{Ab}$ in a Drosophila model of $\mathrm{PD}^{30}$ (Figure $8 \mathrm{H}$ ). As depicted in Figure 8H, staining was apparent in both the cellular cortex (arrows) and inner neuropil areas (asterisks). In flies, the cell bodies of neurons and glia are concentrated in the peripheral cortex (arrows), whereas the inner neuropil (asterisks) contains the processes of neurons and glial cells. The increased staining apparent in some cortical and neuropil areas represents the normal pattern of the elav-GAL4 driver. ${ }^{30}$ Neuropil staining was somewhat more punctate than typically seen with an antibody that recognizes full-length
$\alpha$-Syn (not shown), consistent with preferential inclusion of C-terminally truncated $\alpha$-Syn in inclusions.

Western blot analysis was performed using brain extracts from Tg mice or representative DLB subjects (Figure 9, A and B). Immunoreactivity of the C-terminal $\alpha$-Syn$\mathrm{CCP} A b$ was confined primarily to the soluble fraction (Figure 9A). In contrast to LB509, the C-terminal $\alpha$-SynCCP Ab detected a C-terminal fragment running just under FL $\alpha$-Syn in both Tg mouse models of PD and in human DLB extracts (Figure 9A, lanes 3-6). In addition, the C-terminal $\alpha$-SynCCP Ab detected a prominent band running at approximately $40 \mathrm{kd}$, which is similar to the results observed after application of the $\mathrm{N}$-terminal $\alpha$-SynCCP Ab. No staining was seen in non-Tg control mice either by $\mathrm{IH}$ or by Western blot analysis (Figures $8 \mathrm{~A}$ and 9 ). This probably reflects the fact that the peptide used as an immunogen to generate the C-terminal $\alpha$-SynCCP Ab is not conserved in mouse.

In a final set of experiments, IP studies were performed to determine whether the $\mathrm{C}$-terminal $\alpha$-SynCCP Ab is preferentially a conformational-specific Ab. To accomplish this, cell-free assays using recombinant $\alpha$-Syn were performed in the presence or absence of calpain I. Samples were then incubated with the C-terminal $\alpha$-SynCCP $\mathrm{Ab}$ overnight at $4^{\circ} \mathrm{C}$ either under nondenaturing conditions (PBS only) or under denaturing conditions (radioimmunoprecipitation assay buffer). After the addition of protein $G$ to pull down immune complexes, samples were analyzed by Western blot analysis using FL $\alpha$-Syn AB5038. Figure $9 \mathrm{C}$ depicts the results of such an experiment and shows that the $\mathrm{C}$-terminal $\alpha$-SynCCP Ab did not immunoprecipitate $\mathrm{FL} \alpha$-Syn under nondenaturing conditions but did pull down several calpain-cleaved fragments. In contrast, if IP experiments were performed under denaturing conditions now, the C-terminal $\alpha$-SynCCP Ab preferentially recognized FL $\alpha$-Syn but not calpain-cleaved fragments (Figure 9C). These results suggest that the C-terminal $\alpha$-SynCCP Ab may recognize a conformational epitope of calpain-cleaved $\alpha$-Syn under native conditions. However, after denaturation of $\alpha$-Syn to a linear peptide, specificity to calpain-cleaved fragments of $\alpha$-Syn is lost, and now the antibody seems to recognize both $\mathrm{FL} \alpha$-Syn and C-terminal fragments.

\section{Discussion}

The present report demonstrates that calpain can cleave $\alpha$-Syn in vitro, leading to its aggregation and adoption of a $\beta$-sheet conformation. The cleavage of $\alpha$-Syn at either the $\mathrm{N}$ - or C-terminal end of $\alpha$-Syn could be detected in the PD brain and in the DLB brain using two site-directed calpaincleavage antibodies. These data suggest that calpain may link $\alpha$-Syn processing to its disease-linked aggregation and formation of LBs in various $\alpha$-synucleinopathies. Although numerous studies have demonstrated the presence of truncated species of $\alpha$-Syn in PD and DLB, ${ }^{10-12,33}$ the identity of the protease responsible for this proteolytic processing is unknown. A likely candidate for this processing role of $\alpha$-Syn is the ubiquitin proteosome, and several studies have supported a role for the proteosome in the metabolism of 


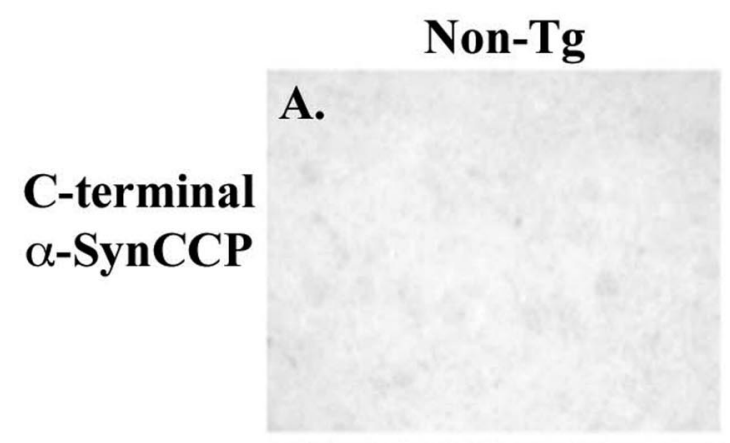

PDGF- $\alpha-S y n$ wt Line D
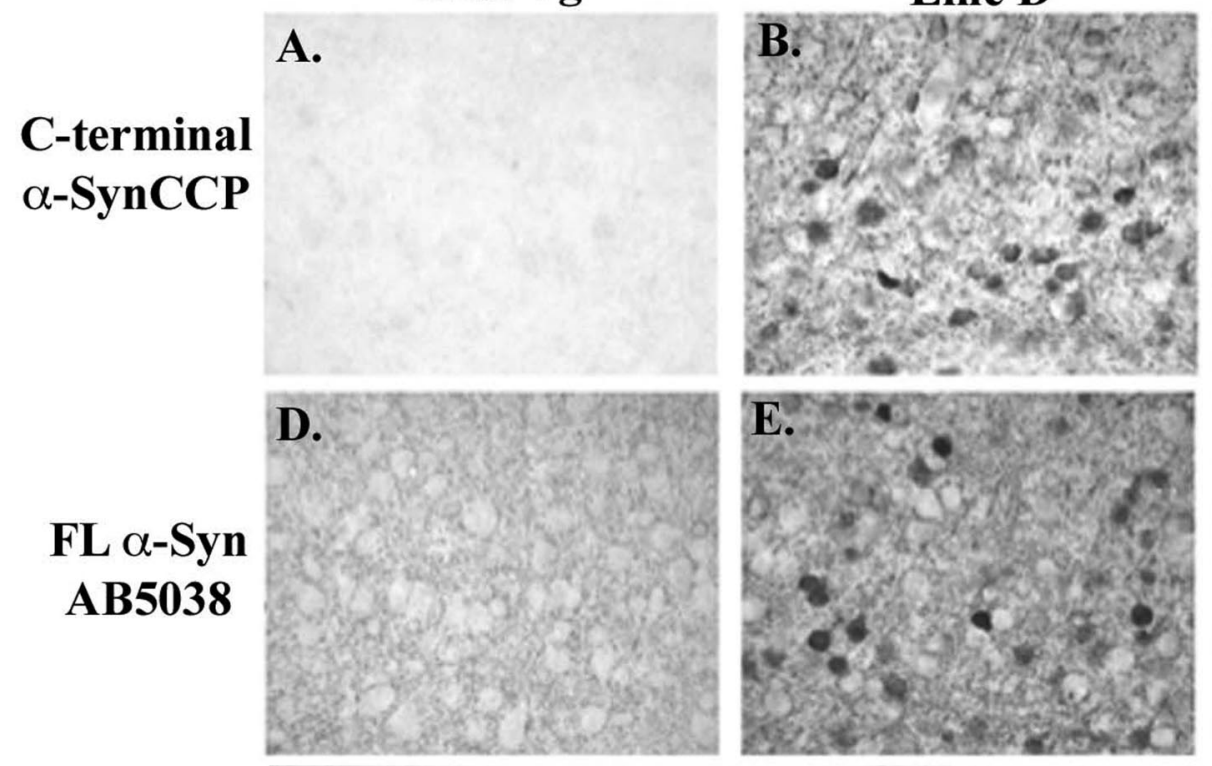

mThy1- $\alpha-S y n$ wt

Line 61
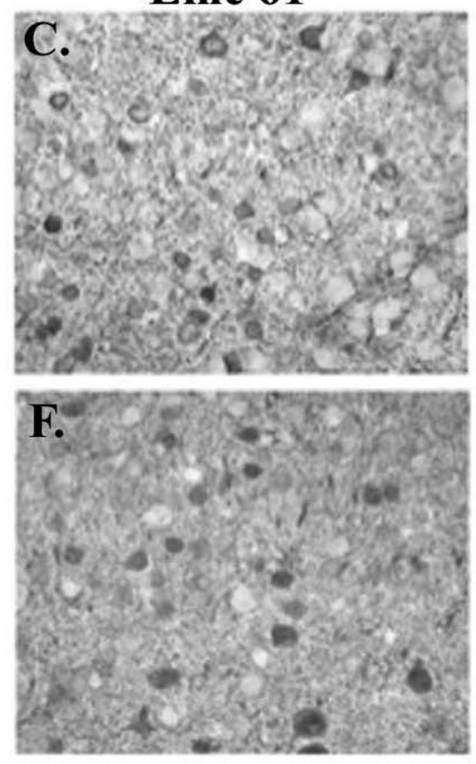

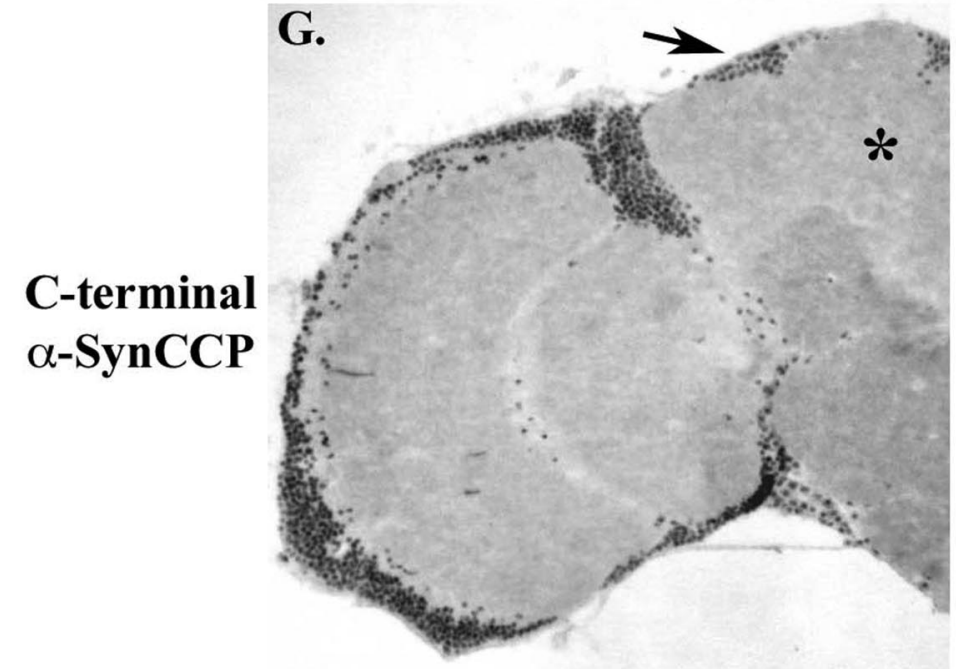

Control

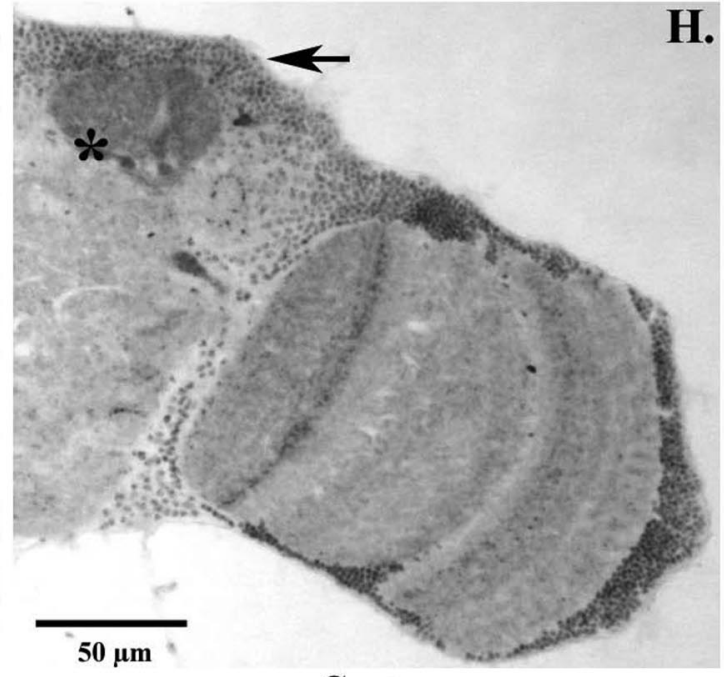

$\alpha-$ Syn

Figure 8. Comparison of C-terminal calpain-cleaved $\alpha$-Syn immunoreactivity from several different animal models of PD. A-F: Panels are from vibratome sections from the brains of mice immunostained with either the C-terminal $\alpha$-SynCCP Ab (A-C) or a commercially available FL $\alpha$-Syn Ab from Chemicon AB5038 (D-F). After application of the C-terminal $\alpha$-SynCCP Ab, immunoreactivity within neurons of the neocortex was observed in two different transgenic mice expressing wild-type $\alpha$-Syn under a PDGF promoter (B) or in a line expressing $\alpha$-Syn under Thy-1 promoter $(\mathbf{C})$. E and $\mathbf{F}$ : A similar staining profile was observed using the FL $\alpha$-Syn Ab. A and D: No staining with either antibody was observed in non-Tg control mice. $\mathbf{G}$ and $\mathbf{H}$ : Detection of the C-terminal calpain-cleavage fragment of $\alpha$-Syn in a Drosophila model of PD. Paraffin-embedded frontal brain sections at the level of the mushroom bodies from 20-day-old flies were immunostained with the C-terminal $\alpha$-SynCCP Ab (DAB staining) and counterstained with hematoxylin. G: The control genotype (elav-GAL/+). H: $\alpha$-Syn expressed in a pan-neural pattern under the control of the elav-GAL driver. Arrows, the peripheral cortex; asterisks, the inner neuropil.

$\alpha$-Syn. ${ }^{11,34}$ However, this is still subject to debate because other studies have failed to show any relationship between $\alpha$-Syn processing and the proteosome. ${ }^{35-37}$ In addition, numerous studies have demonstrated a diminished activity of the proteosome in PD.,38-41 Based on this observation, it is difficult to reconcile how a compromised proteosome could lead to enhanced proteolytic processing of the $\alpha$-Syn.

Another potential protease that may be involved in proteolytic processing of $\alpha$-Syn is caspase-3. Several studies have demonstrated a role for caspase activation and the cleavage of cellular proteins in PD. ${ }^{41-43}$ How- ever, examination of the protein sequence of $\alpha$-Syn did not reveal any consensus caspase sequences, and furthermore, we were unable to digest $\alpha$-Syn in the presence of activated caspase-3 (data not shown). This together with the lack of any studies demonstrating $\alpha$-Syn is a substrate for caspase-mediated cleavage suggests that this to be an unlikely role for this family of proteases.

In the present study, we demonstrate a role for the ubiquitous family of proteases known as calpains as potential proteolytic mediators of $\alpha$-Syn. Calpain activation has been demonstrated to occur in the PD brain ${ }^{44}$ and in 

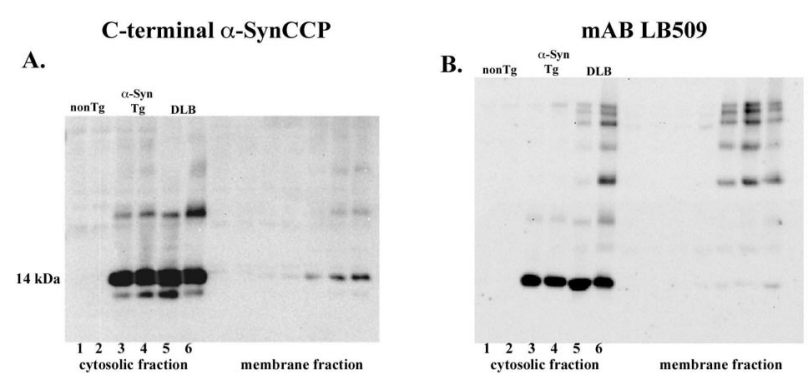

C.

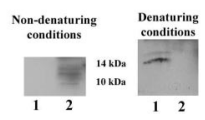

Figure 9. Detection of the C-terminal calpain-cleavage fragment of $\alpha$-Syn by Western blot analysis. Cytosolic and membrane fractions were prepared from nonTg mice (lanes $\mathbf{1}$ and $\mathbf{2}$ ), Tg mice overexpressing wild-type or mutant A53T $\alpha$-Syn under the PDGF promoter (lanes 3 and 4), or from two representative DLB cases (lanes 5 and $\mathbf{6}$ ). Blots were probed either with the C-terminal $\alpha$-SynCCP Ab (A) or with mAb LB509 (B). The C-terminal fragment of $\alpha$-Syn was detected by $\alpha$-SynCCP Ab in soluble fractions but not by LB509 (band running just under full-length, $14 \mathrm{kd}$ ). C: IP experiments with the C-terminal $\alpha$-SynCCP Ab incubated with control $\alpha$-Syn (lane 1) or digested with calpain I (lane 2) under nondenaturing or denaturing conditions. Data suggest the C-terminal $\alpha$-SynCCP Ab is a conformational-specific $\mathrm{Ab}$ whose epitope is lost after denaturation of $\alpha$-Syn.

animal models of PD. ${ }^{45,46}$ Moreover, inhibition of calpains prevents behavioral deficits in an 1-methyl-4-phenyl1,2,3,6-tetrahydropyridine mouse model of PD. ${ }^{47}$ Previous studies have demonstrated that $\alpha$-Syn is a suitable substrate for calpain. ${ }^{19,20}$ Our studies provide evidence that calpain fits the criteria as the protease linking $\alpha$-Syn to its pathological form: 1) $\alpha$-Syn is rapidly and simultaneously cleaved at the $\mathrm{N}$ - and $\mathrm{C}$-terminal regions by calpain; 2) cleavage of $\alpha$-Syn by calpain leads to the generation of high-molecular weight species and converts $\alpha$-Syn from a random coil to a $\beta$-sheet structure, a key step that enhances the ability of $\alpha$-Syn to aggregate ${ }^{7}$; and 3) calpain-cleaved species of $\alpha$-Syn were present in the preponderance of LBs quantified in the human PD and DLB brain and colocalized with active calpain in neurons. In this manner, we detected activated calpain I surrounding Lewy bodies containing calpain-cleaved $\alpha$-Syn. These data suggest that after cleavage of $\alpha$-Syn by calpain I, $\alpha$-Syn aggregates may be deposited within Lewy body structures. Taken together our findings suggest that calpain may be the molecular switch turning on the toxic gain of function of $\alpha$-Syn.

Our data demonstrating the cleavage of $\alpha$-Syn by calpain in a cell-free system are in complete agreement with Li et al, ${ }^{12}$ who also reported an increase in aggregated $\alpha$-Syn after C-terminal cleavage. However, our results are in contrast to those reported by Mishizen-Eberz et $\mathrm{al}^{20}$ who showed that rather than promoting aggregation, calpain cleavage of soluble $\alpha$-Syn prevents fibrillization. In this regard, Mishizen-Eberz et $\mathrm{al}^{20}$ demonstrated that calpain cleavage near the middle of soluble $\alpha$-Syn can generate fragments of $\alpha$-Syn that are unable to selffibrillize and that also prevent FL $\alpha$-Syn from fibrillizing. At the present time, we are unsure of the reason for the discrepancy between our results and the study of Mishizen-Eberz et al. One possibility is that data supporting their conclusion consisted of a Western blot using a monoclonal antibody (Syn 303), which recognizes epitopes at amino acids 2 to 4 of $\alpha$-Syn. Our results suggest that calpain cleaves $\alpha$-Syn between amino acid 9 and 10, and therefore, this antibody would be unable to detect aggregates of $\alpha$-Syn because the epitope for the antibody would have been lost. Another possibility is the difference in starting material (soluble versus fibrillized $\alpha$-Syn) between the studies. Collectively, these studies and our present results suggest that the action of calpain on $\alpha$-Syn may be more nuanced than originally thought depending on the initial state of $\alpha$-Syn (soluble versus fibrillized). Therefore, before calpain I can become a target for the treatment of $\alpha$-synucleinopathies, further studies are warranted to clarify these different patterns of calpain cleavage of $\alpha$-Syn.

Demonstration of the calpain-cleavage of $\alpha$-Syn was confirmed using two different site-directed Abs. Extensive characterization of these antibodies was performed using cell-free assays and in vitro as well as in vivo models of calpain activation. Although both antibodies labeled LBs and Lewy neurites in PD/DLB brains, there were distinct differences between the two Abs. The N-terminal antibody seemed to be highly selective for the calpaincleaved fragment of $\alpha$-Syn by $\mathrm{IH}$ and by Western blot analysis. In contrast, the $\mathrm{C}$-terminal $\mathrm{Ab}$ seemed to react with $\mathrm{FL} \alpha$-Syn as well as with $\mathrm{C}$-terminal fragments. Thus, we cannot say with certainty that the staining observed with the $\mathrm{C}$-terminal $\mathrm{Ab}$ in $\mathrm{IH} / \mathrm{IF}$ experiments was only attributable to immunoreactivity to calpain-cleaved fragments of $\alpha$-Syn. However, several pieces of data suggest the C-terminal $\alpha$-SynCCP Ab is a conformational epitopespecific antibody, and therefore, the staining we observed might reflect a preferential immunoreactivity to the calpain-cleaved fragments of $\alpha$-Syn. First, we compared the immunoreactivity of the C-terminal Ab with LB509 in DLB tissue sections. Coincidentally, the epitope for LB509 is identical to that of the C-terminal Ab with the exception of two additional $\mathrm{N}$-terminal amino acids (Figure 1). Because the LB509 Ab is specific for $F L \alpha$-Syn, it would be expected that double-label experiments using these two Abs would indicate a high degree of overlap after $\mathrm{IH}$ or IF analysis. However, this was not the case: although there were regions of overlap where colocalization was evident, there was a clear spatial resolution between the two Abs in labeled structures. For example, in LBs, C-terminal $\alpha$-SynCCP Ab immunoreactivity was predominantly within the core of the LB, whereas that of LB509 was throughout the entire LB. A spatial separation between these two Abs was also observed in Lewy neurites. Second, in single-labeled experiments using the $C$-terminal $\alpha$-SynCCP Ab, we often observed staining that was rough and aggregated in its appearance (Figure 7B, right panel). This was never the case for LB509, which always gave a homogenous staining pattern. This suggests that the two Abs are recognizing distinct epitopes within $\alpha$-Syn. Third, only the C-terminal $\alpha$-SynCCP Ab and not LB509 detected a C-terminal 12-kd fragment of $\alpha$-Syn by Western blot analysis in brain tissue extracts from Tg PD mice or DLB subjects. Finally, IP experiments using the C-terminal $\alpha$-SynCCP Ab demonstrated it to be a 
conformational epitope-specific Ab. These results suggest that in situ, the C-terminal $\alpha$-SynCCP Ab may preferentially recognize calpain-cleaved $\alpha$-Syn and, taken together with the data using the $\mathrm{N}$-terminal $\alpha$-SynCCP Ab, support a role for calpain cleavage of $\alpha$-Syn in DLB and PD.

Although this report focuses on proteolytic processing of $\alpha$-Syn as a mechanism leading to the aggregation of $\alpha$-Syn, various other factors can transform natively folded $\alpha$-Syn into $\beta$-folded structures, which have the propensity to aggregate (see review ${ }^{7}$ ). Of particular importance in this regard is the phosphorylation of $\alpha$-Syn, which has been shown to be a critical step leading to fibrillization. Selective phosphorylation of $\alpha$-Syn at Ser129 has been demonstrated in DLB and PD brains and enhances the aggregation of $\mathrm{FL} \alpha$-Syn in vitro. ${ }^{48}$ Moreover, mutation of Ser129 to alanine blocks subsequent phosphorylation and prevents dopaminergic neuronal cell loss in a Drosophila model of PD. ${ }^{49}$ These same authors, however, found that blocking phosphorylation of Ser129 enhances the aggregation of $\alpha$-Syn. The authors concluded, therefore, that aggregation of $\alpha$-Syn may actually protect cells from neurotoxicity because phosphorylation of $\alpha$-Syn "favors the maintenance of $\alpha$-Syn in a soluble, toxic form." 49 In the present study, we have demonstrated the calpaincleavage of $\alpha$-Syn leading to its aggregation. It is interesting to speculate whether such modification prevents the phosphorylation of $\alpha$-Syn at Ser129 and thus serves a protective role. Further studies examining the relationship between calpain cleavage of $\alpha$-Syn and its phosphorylation are warranted to address this question.

In summary, we have demonstrated that cleavage of $\alpha$-Syn by calpain I leads to the formation of calpain-cleaved aggregates of $\alpha$-Syn in DLB and PD. Our findings suggest that calpain I may participate in the disease-linked aggregation of $\alpha$-Syn, and these data provide a general mechanism for the initiation and the evolution of Lewy body formation in various $\alpha$-synucleinopathies.

\section{References}

1. Spillantini MG, Schmidt ML, Lee VM, Trojanowski JQ, Jakes R, Goedert M: Alpha-synuclein in Lewy bodies. Nature 1997, 388:839-840

2. McKeith IG, Galasko D, Kosaka K, Perry EK, Dickson DW, Hansen LA, Salmon DP, Lowe J, Mirra SS, Byrne EJ, Lennox G, Quinn NP, Edwardson JA, Ince PG, Bergeron C, Burns A, Miller BL, Lovestone S, Collerton D, Jansen EN, Ballard C, de Vos RA, Wilcock GK, Jellinger $\mathrm{KA}$, Perry $\mathrm{RH}$ : Consensus guidelines for the clinical and pathologic diagnosis of dementia with Lewy bodies (DLB): report of the consortium on DLB international workshop. Neurology 1996, 47:1113-1124

3. Dawson TM, Dawson VL: Molecular pathways of neurodegeneration in Parkinson's disease. Science 2003, 302:819-822

4. Gibb WR: Idiopathic Parkinson's disease and the Lewy body disorders. Neuropathol Appl Neurobiol 1986, 12:223-234

5. Barber R, Panikkar A, McKeith IG: Dementia with Lewy bodies: diagnosis and management. Int J Geriatr Psychiatry 2001, 16(Suppl 1):S12-S18

6. Dickson DW: Alpha-synuclein and the Lewy body disorders. Curr Opin Neurol 2001, 14:423-432

7. Lundvig D, Lindersson E, Jensen PH: Pathogenic effects of alphasynuclein aggregation. Brain Res Mol Brain Res 2005, 134:3-17

8. Cookson MR: The biochemistry of Parkinson's disease. Annu Rev Biochem 2005, 74:29-52

9. Lee MK, Stirling W, Xu Y, Xu X, Qui D, Mandir AS, Dawson TM,
Copeland NG, Jenkins NA, Price DL: Human alpha-synuclein-harboring familial Parkinson's disease-linked Ala-53 $\rightarrow$ Thr mutation causes neurodegenerative disease with alpha-synuclein aggregation in transgenic mice. Proc Natl Acad Sci USA 2002, 99:8968-8973

10. Baba M, Nakajo S, Tu PH, Tomita T, Nakaya K, Lee VM, Trojanowski $J Q$, Iwatsubo T: Aggregation of alpha-synuclein in Lewy bodies of sporadic Parkinson's disease and dementia with Lewy bodies. Am J Pathol 1998, 152:879-884

11. Liu CW, Giasson BI, Lewis KA, Lee VM, Demartino GN, Thomas PJ: A precipitating role for truncated alpha-synuclein and the proteasome in alpha-synuclein aggregation: implications for pathogenesis of Parkinson's disease. J Biol Chem 2005, 280:22670-22678

12. Li W, West N, Colla E, Pletnikova O, Troncoso JC, Marsh L, Dawson TM, Jakala P, Hartmann T, Price DL, Lee MK: Aggregation promoting C-terminal truncation of alpha-synuclein is a normal cellular process and is enhanced by the familial Parkinson's disease-linked mutations. Proc Natl Acad Sci USA 2005, 102:2162-2167

13. Giasson BI, Duda JE, Quinn SM, Zhang B, Trojanowski JQ, Lee VM: Neuronal alpha-synucleinopathy with severe movement disorder in mice expressing A53T human alpha-synuclein. Neuron 2002, 34:521-533

14. Serpell LC, Berriman J, Jakes R, Goedert M, Crowther RA: Fiber diffraction of synthetic alpha-synuclein filaments shows amyloid-like cross-beta conformation. Proc Natl Acad Sci USA 2000, 97:4897-4902

15. Kanda S, Bishop JF, Eglitis MA, Yang Y, Mouradian MM: Enhanced vulnerability to oxidative stress by alpha-synuclein mutations and C-terminal truncation. Neuroscience 2000, 97:279-284

16. Tofaris GK, Garcia Reitbock P, Humby T, Lambourne SL, O'Connell M, Ghetti B, Gossage H, Emson PC, Wilkinson LS, Goedert M, Spillantini MG: Pathological changes in dopaminergic nerve cells of the substantia nigra and olfactory bulb in mice transgenic for truncated human alpha-synuclein(1-120): implications for Lewy body disorders. J Neurosci 2006, 26:3942-3950

17. Vanderklish PW, Bahr BA: The pathogenic activation of calpain: a marker and mediator of cellular toxicity and disease states. Int J Exp Pathol 2000, 81:323-339

18. Glading A, Lauffenburger DA, Wells A: Cutting to the chase: calpain proteases in cell motility. Trends Cell Biol 2002, 12:46-54

19. Mishizen-Eberz AJ, Guttmann RP, Giasson BI, Day GA III, Hodara R, Ischiropoulos H, Lee VM, Trojanowski JQ, Lynch DR: Distinct cleavage patterns of normal and pathologic forms of alpha-synuclein by calpain I in vitro. J Neurochem 2003, 86:836-847

20. Mishizen-Eberz AJ, Norris EH, Giasson BI, Hodara R, Ischiropoulos H, Lee VM, Trojanowski JQ, Lynch DR: Cleavage of alpha-Synuclein by calpain: potential role in degradation of fibrillized and nitrated species of alpha-synuclein. Biochemistry 2005, 44:7818-7829

21. Murray IV, Giasson BI, Quinn SM, Koppaka V, Axelsen PH, Ischiropoulos $\mathrm{H}$, Trojanowski JQ, Lee VM: Role of alpha-synuclein carboxyterminus on fibril formation in vitro. Biochemistry 2003, 42:8530-8540

22. Tompa P, Buzder-Lantos P, Tantos A, Farkas A, Szilagyi A, Banoczi Z, Hudecz F, Friedrich P: On the sequential determinants of calpain cleavage. J Biol Chem 2004, 279:20775-20785

23. Rohn TT, Rissman RA, Head E, Cotman CW: Caspase activation in the Alzheimer's disease brain: tortuous and torturous. Drug News Perspect 2002, 15:549-557

24. Reimertz C, Kogel D, Lankiewicz S, Poppe M, Prehn JH: Ca(2+)induced inhibition of apoptosis in human SH-SY5Y neuroblastoma cells: degradation of apoptotic protease activating factor-1 (APAF-1). J Neurochem 2001, 78:1256-1266

25. Hou ST, Jiang SX, Desbois A, Huang D, Kelly J, Tessier L, Karchewsk L, Kappler J: Calpain-cleaved collapsin response mediator protein-3 induces neuronal death after glutamate toxicity and cerebral ischemia. J Neurosci 2006, 26:2241-2249

26. Mouser PE, Head E, Ha KH, Rohn TT: Caspase-mediated cleavage of glial fibrillary acidic protein within degenerating astrocytes of the Alzheimer's disease brain. Am J Pathol 2006, 168:936-946

27. Gomez-Isla T, Irizarry MC, Mariash A, Cheung B, Soto O, Schrump S, Sondel J, Kotilinek L, Day J, Schwarzschild MA, Cha JH, Newell K, Miller DW, Ueda K, Young AB, Hyman BT, Ashe KH: Motor dysfunction and gliosis with preserved dopaminergic markers in human alpha-synuclein A30P transgenic mice. Neurobiol Aging 2003, 24:245-258

28. Masliah E, Rockenstein E, Veinbergs I, Mallory M, Hashimoto M, 
Takeda A, Sagara Y, Sisk A, Mucke L: Dopaminergic loss and inclusion body formation in alpha-synuclein mice: implications for neurodegenerative disorders. Science 2000, 287:1265-1269

29. Rockenstein E, Mallory M, Hashimoto M, Song D, Shults CW, Lang I, Masliah E: Differential neuropathological alterations in transgenic mice expressing alpha-synuclein from the platelet-derived growth factor and Thy-1 promoters. J Neurosci Res 2002, 68:568-578

30. Feany MB, Bender WW: A Drosophila model of Parkinson's disease. Nature 2000, 404:394-398

31. Kim TD, Paik SR, Yang CH: Structural and functional implications of C-terminal regions of alpha-synuclein. Biochemistry 2002, 41:13782-13790

32. Jucker M, Walker LC, Martin LJ, Kitt CA, Kleinman HK, Ingram DK, Price DL: Age-associated inclusions in normal and transgenic mouse brain. Science 1992, 255:1443-1445

33. Campbell BC, McLean CA, Culvenor JG, Gai WP, Blumbergs PC, Jakala P, Beyreuther K, Masters CL, Li QX: The solubility of alphasynuclein in multiple system atrophy differs from that of dementia with Lewy bodies and Parkinson's disease. J Neurochem 2001, 76:87-96

34. Bennett MC, Bishop JF, Leng Y, Chock PB, Chase TN, Mouradian MM: Degradation of alpha-synuclein by proteasome. J Biol Chem 1999, 274:33855-33858

35. Ancolio K, Alves da Costa C, Ueda K, Checler F: Alpha-synuclein and the Parkinson's disease-related mutant Ala53Thr-alpha-synuclein do not undergo proteasomal degradation in HEK293 and neuronal cells. Neurosci Lett 2000, 285:79-82

36. Paxinou E, Chen Q, Weisse M, Giasson BI, Norris EH, Rueter SM, Trojanowski JQ, Lee VM, Ischiropoulos $\mathrm{H}$ : Induction of alphasynuclein aggregation by intracellular nitrative insult. J Neurosci 2001, 21:8053-8061

37. Kim SJ, Sung JY, Um JW, Hattori N, Mizuno Y, Tanaka K, Paik SR, Kim $J$, Chung KC: Parkin cleaves intracellular alpha-synuclein inclusions via the activation of calpain. J Biol Chem 2003, 278:41890-41899

38. McNaught KS, Olanow CW, Halliwell B, Isacson O, Jenner P: Failure of the ubiquitin-proteasome system in Parkinson's disease. Nat Rev Neurosci 2001, 2:589-594

39. McNaught KS, Jenner P: Proteasomal function is impaired in substantia nigra in Parkinson's disease. Neurosci Lett 2001, 297:191-194

40. McNaught KS, Belizaire R, Isacson O, Jenner P, Olanow CW: Altered proteasomal function in sporadic Parkinson's disease. Exp Neurol 2003, 179:38-46

41. Blandini F, Sinforiani E, Pacchetti C, Samuele A, Bazzini E, Zangaglia R, Nappi G, Martignoni E: Peripheral proteasome and caspase activity in Parkinson disease and Alzheimer disease. Neurology 2006, 66:529-534

42. Newman J, Rissman RA, Sarsoza F, Kim RC, Dick M, Bennett DA, Cotman CW, Rohn TT, Head E: Caspase-cleaved tau accumulation in neurodegenerative diseases associated with tau and alpha-synuclein pathology. Acta Neuropathol (Berl) 2005, 110:135-144

43. Hartmann A, Hunot S, Michel PP, Muriel MP, Vyas S, Faucheux BA, Mouatt-Prigent A, Turmel H, Srinivasan A, Ruberg M, Evan Gl, Agid Y, Hirsch EC: Caspase-3: a vulnerability factor and final effector in apoptotic death of dopaminergic neurons in Parkinson's disease. Proc Natl Acad Sci USA 2000, 97:2875-2880

44. Mouatt-Prigent A, Karlsson JO, Agid Y, Hirsch EC: Increased Mcalpain expression in the mesencephalon of patients with Parkinson's disease but not in other neurodegenerative disorders involving the mesencephalon: a role in nerve cell death? Neuroscience 1996 73:979-987

45. Ray SK, Wilford GG, Ali SF, Banik NL: Calpain upregulation in spinal cords of mice with 1-methyl-4-phenyl-1,2,3,6-tetrahydropyridine (MPTP)-induced Parkinson's disease. Ann NY Acad Sci 2000, 914:275-283

46. Ray SK, Matzelle DD, Wilford GG, Hogan EL, Banik NL: Increased calpain expression is associated with apoptosis in rat spinal cord injury: calpain inhibitor provides neuroprotection. Neurochem Res 2000, 25:1191-1198

47. Crocker SJ, Smith PD, Jackson-Lewis V, Lamba WR, Hayley SP, Grimm E, Callaghan SM, Slack RS, Melloni E, Przedborski S, Robertson GS, Anisman H, Merali Z, Park DS: Inhibition of calpains prevents neuronal and behavioral deficits in an MPTP mouse model of Parkinson's disease. J Neurosci 2003, 23:4081-4091

48. Fujiwara H, Hasegawa M, Dohmae N, Kawashima A, Masliah E, Goldberg MS, Shen J, Takio K, Iwatsubo T: Alpha-synuclein is phosphorylated in synucleinopathy lesions. Nat Cell Biol 2002, 4:160-164

49. Chen L, Feany MB: Alpha-synuclein phosphorylation controls neurotoxicity and inclusion formation in a Drosophila model of Parkinson disease. Nat Neurosci 2005, 8:657-663 